\title{
INDICADORES QUÍMICOS DE QUALIDADE DA MATÉRIA ORGÂNICA DE SOLO DA SUB-BACIA DO RIO DAS MORTES SOB MANEJOS DIFERENCIAIS DE CAFEEIRO
}

\author{
Antônio Claret Oliveira Júnior* \\ Instituto Nacional de Colonização e Reforma Agrária, Av. Afonso Pena, 2403, 79002-073 Campo Grande - MS, Brasil \\ Carlos Alberto Silva, Nilton Curi e Luiz Roberto Guimarães Guilherme \\ Departamento de Ciência do Solo, Universidade Federal de Lavras, CP 3037, 37200-000 Lavras - MG, Brasil \\ Otacílio José Passos Rangel \\ Escola Agrotécnica Federal de Alegre, CP 47, 29500-000 Alegre-ES, Brasil
}

Recebido em 3/1/08; aceito em 14/5/08; publicado na web em 22/9/08

\begin{abstract}
CHEMICAL INDICATORS OF THE QUALITY OF ORGANIC MATTER OF SOIL FROM THE RIO DAS MORTES WATERSHED UNDER DIFFERENT COFFEE PLANT MANAGEMENTS. This work evaluated the chemical quality of organic matter (OM) of a Brazilian Oxisol cultivated with coffee plants, under organic and conventional managements. Total organic C (TOC), light fraction $\mathrm{C}$ (LF-C) and $\mathrm{C}$ in humic (HA-C) and fulvic (FA-C) acids fractions was measured. Amongst the evaluated indexes, TOC and LF-C discriminated better OM attributes as a function of management. The stratification ratio $\left(\mathrm{TOC}_{5-10 \mathrm{~cm}} / \mathrm{TOC}_{10-20 \mathrm{~cm}}\right)$ did not show differences between the systems studied. The organic system can contribute to the sustainability of coffee plantations in Brazil, because it maintains the chemical attributes of $\mathrm{OM}$ closer to the indexes verified under forest conditions.
\end{abstract}

Keywords: light fraction; humic substances; stratification ratio.

\section{INTRODUÇÃO}

A sub-bacia do Rio das Mortes (Figura 1), situada no centro-sul de Minas Gerais, mesorregião Campos das Vertentes, engloba (total ou parcialmente) 26 municípios, ocupando uma área de $6.500 \mathrm{~km}^{2}$. Atualmente, cerca de $25 \%$ dos 76.000 ha sob uso agrícola dessa subbacia estão ocupados pela cafeicultura, com destaque para sua porção oeste, onde essa cultura chega a ocupar até $65 \%$ da área plantada de

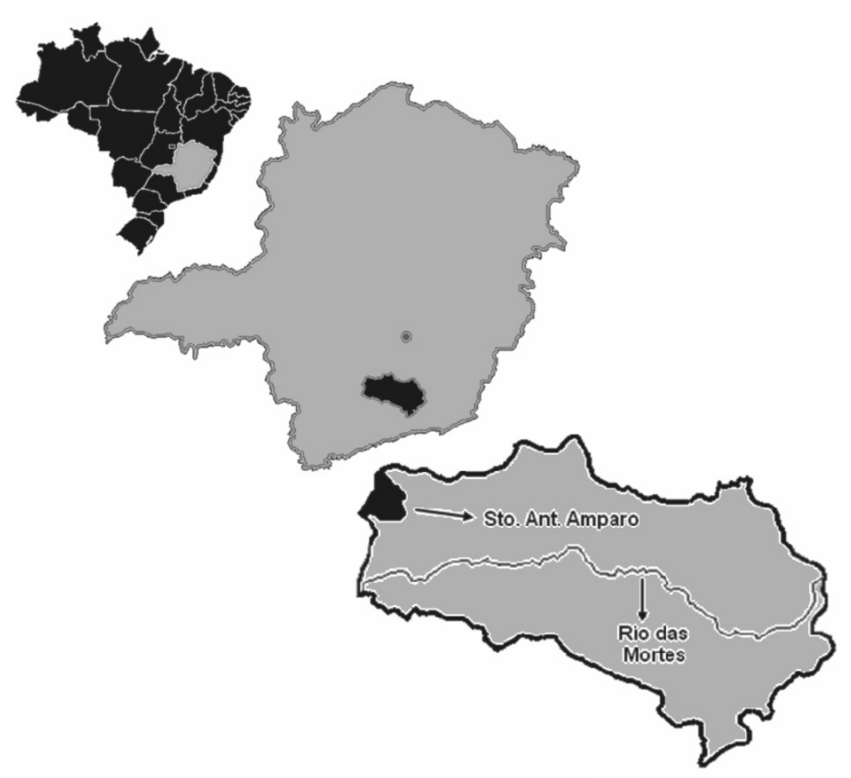

Figura 1. Limites da sub-bacia do Rio das Mortes e sua localização no estado de Minas Gerais, destacando-se o rio das Mortes e o município de Santo Antônio do Amparo (principal produtor de café da sub-bacia)

*e-mail: antoniocoliveirajr@gmail.com alguns municípios. ${ }^{1}$ Nas áreas de produção de café de Minas Gerais, predomina o manejo convencional, com emprego de defensivos químicos, baixo uso de adubos orgânicos e número reduzido de plantas por área, com impactos diretos sobre a qualidade do solo e do ambiente como um todo. Por outro lado, tem ganhado projeção o cultivo orgânico do cafeeiro que, do ponto de vista de manejo, se diferencia do sistema convencional, pela substituição da adubação química pela orgânica/verde e não aplicação de defensivos, sendo esta uma das formas de melhorar a qualidade do solo. ${ }^{2}$ Mesmo no manejo orgânico, a adubação fosfatada é essencial e, nesse caso, essa prática é realizada por meio da aplicação de fosfatos naturais de baixa reatividade ou, em alguns casos, do uso de superfosfato simples e termofosfato.

Diferentes manejos de uma mesma cultura, sob condições equiparáveis, propiciam modificações na matéria orgânica do solo, com reflexos diretos sobre sua qualidade. ${ }^{3}$ Atualmente, o conceito de qualidade do solo está atrelado à sua capacidade de funcionar dentro dos limites do ecossistema, sustentando a produtividade biológica, promovendo a saúde humana, sem prejuízo da qualidade ambiental. ${ }^{4}$ Em áreas onde não são adotadas práticas de manejo conservacionista, têm sido verificadas perdas de até $50 \%$ do $\mathrm{C}$ original do solo, em menos de 10 anos de cultivo. ${ }^{5} \mathrm{~A}$ introdução de um manejo conservacionista pode auxiliar na recuperação da qualidade do solo, sobretudo daqueles degradados. ${ }^{6}$ Além da redução nos teores de C, é comum uma piora na qualidade da matéria orgânica, uma vez que, com o cultivo, as frações mais biodisponíveis (C-fração leve, C-biomassa microbiana, $\mathrm{C}$ orgânico dissolvido etc.) são consumidas pela microbiota do solo, gerando, ao longo do tempo, enriquecimento relativo das frações orgânicas mais recalcitrantes ${ }^{7}$ (C-substâncias húmicas, C-material carbonizado etc. ${ }^{8}$ ).

Em relação às perdas de matéria orgânica em solo cultivado, quase sempre, o fluxo de $\mathrm{C}$ para a atmosfera ocorre em detrimento do $\mathrm{C}$ armazenado nas camadas mais superficiais do solo. Tendo em vista esse padrão de fluxo, Franzluebbers ${ }^{9}$ propôs o que se convencionou chamar de razão de estratificação (RE), que consiste na 
relação entre o $\mathrm{C}$ orgânico presente nas camadas superficial (0-5 $\mathrm{cm})$ e mais profunda $(12,5-20 \mathrm{~cm})$ do solo. Assim, para solos sob manejo convencional seria esperado um valor de RE menor que 2,0, enquanto que, sob manejo conservacionista (plantio direto), esse valor seria maior que 2,0. Contudo, Franzluebbers ${ }^{9}$ avaliou somente solos norte-americanos, sem levar em conta o $\mathrm{C}$ de solos sob vegetação nativa (áreas-referência), relatando somente que os valores de RE deveriam aumentar à medida que o solo se aproximasse de condições de plena preservação.

Sob cultivo, a maioria dos estudos tem mostrado que o C orgânico total do solo (COT) é pouco sensível para detectar mudanças químicas de curto prazo na matéria orgânica do solo, em função de diferentes manejos. Assim, além do COT, devem ser adotadas outras frações para monitorar, em menor tempo, mudanças nos compartimentos da matéria orgânica do solo e fluxos de $\mathrm{C}$ entre esses compartimentos. Alguns compartimentos de $C$ expressam adequadamente as alterações na qualidade do solo em função do manejo adotado, ${ }^{10}$ sendo exemplo o C associado à fração leve livre (C-FL), determinado pelo fracionamento densimétrico. ${ }^{11,12} \mathrm{~A}$ fração leve compreende a matéria orgânica particulada livre ou intra-agregados, constituindo-se de 10 a $30 \%$ do C orgânico, ${ }^{13}$ mas os seus teores variam com o tipo de solo, clima e manejo, ${ }^{14}$ sendo que, via de regra, mais C-FL é encontrado em solos com maior aporte de resíduos, nos horizontes superficiais, nas áreas sob plantio direto, em sistemas de rotação de culturas etc. ${ }^{15,16}$

Em geral, o C-FL engloba substâncias orgânicas com baixo grau de decomposição, ou seja, em estágio próximo dos resíduos de plantas e distante do húmus, apresentando densidade $\left(\mathrm{g} \mathrm{cm}^{-3}\right)$ próxima de $1 .{ }^{17}$ Em comparação com área de floresta, foi verificada uma diminuição de $94 \%$ nos teores de C-FL nas áreas de cultivo. ${ }^{3}$ Na camada de 0-10 $\mathrm{cm}$ de profundidade, o C-FL foi maior com adubação orgânica que com adubação exclusivamente mineral, onde o aporte de resíduos foi menor. ${ }^{18}$ A relação C-FL/COT também é usada como indicador da qualidade química do solo, sendo que, quanto maior for essa relação, mais conservacionista é o manejo do solo. ${ }^{3}$ Em área de floresta, os valores de C-FL/COT foram até 4,6 vezes maiores que em áreas com uso de adubação orgânica. ${ }^{18}$

As substâncias húmicas são agregados moleculares heterogêneos, cuja estabilidade é essencial na manutenção e recuperação da qualidade do solo e que constituem cerca de 70\% do COT de solos e sedimentos. ${ }^{11,19}$ As frações húmicas são divididas, operacionalmente, em huminas, ácidos húmicos ( $\mathrm{AH}$ ) e ácidos fúlvicos (AF), de acordo com suas solubilidades em diferentes condições de $\mathrm{pH} .{ }^{20} \mathrm{Os} \mathrm{AF}$ são solúveis tanto em meio ácido quanto alcalino, enquanto que os $\mathrm{AH}$ são solúveis somente em meio alcalino. Já as huminas são insolúveis em qualquer meio, alcalino ou ácido. ${ }^{20}$

As relações entre os teores de $\mathrm{C}$ nessas frações podem ser utilizadas como indicadores químicos da qualidade da matéria orgânica, onde os AH se destacam por serem aquela que mais sofre alterações estruturais. ${ }^{21}$ Isso se deve ao fato de os AH representarem a fração intermediária entre estabilização dos compostos pela interação com a matéria mineral (huminas) e a ocorrência de ácidos orgânicos oxidados livres na solução do solo (ácidos fúlvicos livres ou associados). ${ }^{7}$ Nesse sentido, a manutenção de maiores teores de $\mathrm{C}$ na forma de ácidos húmicos (C-AH), em relação aos teores de $\mathrm{C}$ na fração ácido fúlvico (C-AF), indica solos mais preservados, de manejo mais conservacionista. $^{7}$

A relação de maior relevância para o $\mathrm{C}$ presente nas substâncias húmicas é estabelecida entre as frações ácidos húmico e fúlvico (C$\mathrm{AH} / \mathrm{C}-\mathrm{AF}$ ), uma vez que indica a conversão mútua entre essas formas e a mobilidade do $\mathrm{C}$ do solo. Assim, maiores valores de $\mathrm{C}-\mathrm{AH} / \mathrm{C}-\mathrm{AF}$ sinalizam para uma maior condensação de compostos húmicos e, conseqüentemente, maior teor de C orgânico no solo. ${ }^{18}$ Nos trópicos, a intensa mineralização da matéria orgânica e as restrições edáficas à atividade microbiológica e, por conseguinte, à humificação, tornam os valores de $\mathrm{C}-\mathrm{AH} / \mathrm{C}-\mathrm{AF}$ mais reduzidos, em razão da menor probabilidade de condensação dos materiais húmicos do solo. Por outro lado, pode haver perda de C-AF em solo com $\mathrm{pH}$ corrigido pela aplicação de calcário, ${ }^{22}$ pois a correção da acidez implica em aumento da solubilidade dos $\mathrm{AH}$, com conseqüente perda dos $\mathrm{AF}$ por lixiviação. A maior lixiviação de $\mathrm{C}-\mathrm{AF}$ em solo ocorre devido à maior quantidade de radicais carboxílicos, ${ }^{20}$ menor massa molar e a maior solubilidade desta fração ${ }^{22}$ em qualquer faixa de $\mathrm{pH}$.

Na ausência de revolvimento do solo, as diferenças na composição das substâncias húmicas são reguladas principalmente pela atividade microbiana, ${ }^{23}$ ou seja, o abandono da prática de revolvimento do solo favorece a humificação e a formação de moléculas de maior massa molar, favorecendo, portanto, a condensação natural e prevalência de $\mathrm{C}$-AH no solo. ${ }^{24} \mathrm{O}$ cultivo de cafeeiro em área originalmente sob floresta primária, recém-desmatada, acarretou uma diminuição dos teores de $\mathrm{C}$-AH e aumento de $\mathrm{C}$-AF na superfície, enquanto que, em subsuperfície, houve diminuição de ambas as frações. ${ }^{25}$

Na sub-bacia do Rio das Mortes, há uma expressiva escassez de dados a respeito da influência dos diferentes manejos das culturas implantadas sobre as propriedades da matéria orgânica do solo. Assim, este trabalho teve como objetivo avaliar a qualidade química da matéria orgânica do solo mais expressivo geograficamente dessa sub-bacia, cultivado com cafeeiro, sob manejos convencional e orgânico, por meio de indicadores com níveis variáveis de sensibilidade às operações de preparo e cultivo do solo, que exercem forte influência sobre a dinâmica da matéria orgânica e de seus compartimentos $(\mathrm{C}$ orgânico total, $\mathrm{C}$ da fração leve e $\mathrm{C}$ nas frações ácidos húmico e fúlvico), tendo como referência solo sob mata nativa.

\section{PARTE EXPERIMENTAL}

\section{Áreas de estudo}

As áreas de estudo estão localizadas na sub-bacia do Rio das Mortes, mesorregião Campos das Vertentes, centro-sul de Minas Gerais (Figura 1). Essa sub-bacia faz parte da Bacia do Alto Rio Grande (área total de $15.000 \mathrm{~km}^{2}$ ). Foram selecionadas glebas há décadas sob cultivo de cafeeiro, no município de Santo Antônio do Amparo, uma vez que lá se localizam mais de $40 \%$ das áreas de cafeicultura da sub-bacia. ${ }^{1}$

Os sítios de coleta de amostras de solo (Latossolo Vermelho Distrófico típico) foram selecionados com base em estudo anterior, ${ }^{26}$ compreendendo os seguintes manejos: manejo orgânico (Fazenda Cachoeira) - área de manejo orgânico certificado, onde são realizadas, desde 1995, adubações orgânicas (esterco de galinha, húmus de minhoca, composto à base de esterco de gado e cascas de fruto do cafeeiro e dejetos de suíno), calagem, adubação verde (Crotalaria juncea e Cajanus cajan), termofosfato, adubações foliares com micronutrientes e calda bordalesa; manejo convencional (Fazenda Taquaril) - uso de uréia, sulfato de amônio, superfosfato simples, cloreto de potássio, herbicidas, fungicidas, adubações foliares (micronutrientes) e com casca de café.

Como área-referência coletaram-se amostras de solo sob mata nativa (Floresta sub-perenifólia).

\section{Amostragem}

As amostras foram coletadas em abril de 2005, logo após a colheita do café. Estas foram realizadas ao longo de um transecto orientado no sentido do maior comprimento da gleba, no qual foram demarcados 5 pontos eqüidistantes de $20 \mathrm{~m}$. Em cada ponto, foram abertas 3 mini-trincheiras $(0,3 \times 0,3 \times 0,2 \mathrm{~m})$, distanciadas em $10 \mathrm{~m}$, ao 
longo de uma linha imaginária ortogonal ao transecto, onde foram feitas as coletas, num total de 15 mini-trincheiras para cada manejo. Nas áreas de cultivo, as mini-trincheiras foram abertas na projeção da copa do cafeeiro.

Em cada mini-trincheira foram retiradas amostras nas profundidades de 0-5, 5-10 e 10-20 cm. Em cada amostra, determinaram-se os teores de $\mathrm{C}$ orgânico total (COT) e de $\mathrm{C}$ nas frações ácidos húmico (C-AH) e fúlvico (C-AF), em todas as profundidades; e o teor de $\mathrm{C}$ na forma de fração leve $(\mathrm{C}-\mathrm{FL})$ na camada mais superficial $(0-5 \mathrm{~cm})$.

\section{Métodos analíticos}

Para a camada mais superficial, foram realizadas análises químicas de fertilidade e determinada a granulometria, conforme Embrapa ${ }^{27}$ (Tabela 1). Os teores de COT foram determinados pelo método de Walkley e Black modificado, com oxidação das amostras por dicromato de potássio e quantificação indireta do C por titulação com sulfato ferroso amonia$\mathrm{cal}^{28}$ De posse desses valores, determinou-se a razão de estratificação (RE), dividindo-se o teor de COT da camada de solo de $0-5 \mathrm{~cm}$ pelo COT observado na camada de solo de $10-20 \mathrm{~cm} .{ }^{9} \mathrm{O}$ C-FL foi obtido por meio de fracionamento físico-densimétrico do solo, com o uso de $\mathrm{NaI}(\mathrm{d}=$ $1,80 \mathrm{~g} \mathrm{~mL}^{-1}$ ) e sifonamento da fração leve, ${ }^{29}$ quantificando-se o $\mathrm{C}$ deste compartimento da mesma forma que para o COT. ${ }^{28}$

Tabela 1. Atributos químicos e físicos de camadas superficiais de Latossolo Vermelho distrófico típico sob mata (referência) e cultivos (orgânico e convencional) de cafeeiro

\begin{tabular}{|c|c|c|c|}
\hline \multirow{2}{*}{ Atributo } & \multicolumn{3}{|c|}{ Manejo } \\
\hline & Orgânico & Convencional & Mata \\
\hline $\mathrm{pH}$ & 7,4 & 5,3 & 5,1 \\
\hline $\mathrm{P}\left(\mathrm{mg} \mathrm{dm}^{-3}\right)$ & 282,1 & 8,3 & 2,2 \\
\hline $\mathrm{K}\left(\mathrm{mg} \mathrm{dm}^{-3}\right)$ & 156,5 & 223,9 & 63 \\
\hline $\mathrm{Ca}\left(\mathrm{cmol}_{\mathrm{c}} \mathrm{dm}^{-3}\right)$ & 6,7 & 3,4 & 0,9 \\
\hline $\mathrm{Mg}\left(\mathrm{cmol}_{\mathrm{c}} \mathrm{dm}^{-3}\right)$ & 2,4 & 1,5 & 0,8 \\
\hline $\mathrm{t}\left(\mathrm{cmol}_{\mathrm{c}} \mathrm{dm}^{-3}\right)$ & 9,2 & 5,7 & 3,0 \\
\hline $\mathrm{T}\left(\mathrm{cmol}_{\mathrm{c}} \mathrm{dm}^{-3}\right)$ & 10,8 & 8,9 & 9,5 \\
\hline $\mathrm{Al}\left(\mathrm{cmol}_{\mathrm{c}} \mathrm{dm}^{-3}\right)$ & 0,0 & 0,2 & 1,0 \\
\hline Argila $\left(\mathrm{g} \mathrm{kg}^{-1}\right)$ & 390 & 410 & 400 \\
\hline Areia $\left(\mathrm{g} \mathrm{kg}^{-1}\right)$ & 300 & 330 & 320 \\
\hline Silte $\left(\mathrm{g} \mathrm{kg}^{-1}\right)$ & 310 & 260 & 280 \\
\hline
\end{tabular}

$\mathrm{pH}=\mathrm{pH}$ em água; $\mathrm{P}=\mathrm{P}-$ Mehlich $-1 ; \mathrm{K}=$ potássio $; \mathrm{Ca}=$ cálcio; $\mathrm{Mg}$ = magnésio; $\mathrm{t}=$ Capacidade de troca de cátions (CTC) efetiva; $\mathrm{T}=$ CTC potencial; $\mathrm{Al}=$ alumínio trocável.

Os teores de $\mathrm{C}$ das frações húmicas (C-AH e C-AF) do solo foram determinados através do fracionamento químico da matéria orgânica, pelo princípio da solubilidade diferencial das frações húmicas em função do $\mathrm{pH} .{ }^{30}$ Uma massa de 2,5 g de TFSA foi misturada a $20 \mathrm{~mL}$ de $\mathrm{NaOH} 0,1 \mathrm{~mol} \mathrm{~L}^{-1}$ que, após agitação manual e repouso por $24 \mathrm{~h}$, foi centrifugada ( $5000 \mathrm{G}$ por $30^{\prime}$ ). O sobrenadante foi separado e, em seguida, adicionados mais $20 \mathrm{~mL}$ da solução de hidróxido de sódio, deixando-se em repouso por mais $1 \mathrm{~h}$, repetindo-se a centrifugação. Descartou-se o corpo de fundo, não se determinando a fração humina. Em seguida ajustou-se o $\mathrm{pH}$ do extrato alcalino (AH+AF) para 1,0, visando-se à precipitação dos $\mathrm{AH}$, permanecendo os $\mathrm{AF}$ em solução. Após decantação dos AH por $18 \mathrm{~h}$, filtrou-se todo o material em membrana de $0,45 \mu \mathrm{m}$, sob vácuo, para retenção dos AH. Recolheu-se, em separado, ambas as frações ajustando-se seus volumes para $50 \mathrm{~mL}$. Desses volumes, utilizou-se uma alíquota de $5 \mathrm{~mL}$ para determinação dos teores de C-AH e C-AF, através de oxidação por dicromato de potássio e titulação com sulfato ferroso amoniacal.

\section{Estatística}

Todas as variáveis foram submetidas à análise de variância, com as diferenças identificadas pelo teste de Scott-Knott ao nível de 5\% de probabilidade. Quando pertinente, foram feitas análises de correlação simples, associando-se os valores dos compartimentos da matéria orgânica entre si, com a verificação da significância dos coeficientes de correlação (r) efetuada pelo teste t-Student.

\section{RESULTADOS E DISCUSSÃO}

Em outros trabalhos foram encontrados valores de C orgânico maiores tanto para áreas de manejo convencional do cafeeiro, ${ }^{26}$ quanto para áreas de mata. ${ }^{31,32}$ Neste estudo, os teores de COT decresceram na seguinte ordem (profundidade 0-20 cm): mata > café orgânico > café convencional (Tabela 2), pois o manejo orgânico propicia maior armazenamento de matéria orgânica que o convencional, ${ }^{26}$ capaz, portanto, de se aproximar das condições naturais.

Tabela 2. Teores de carbono orgânico total (COT) e razão de estratificação (RE) do COT em diferentes profundidades de Latossolo Vermelho distrófico típico, de áreas de mata e de diferentes manejos de cafeeiro

\begin{tabular}{|c|c|c|c|c|c|}
\hline \multicolumn{6}{|c|}{ Profundidade do solo $(\mathrm{cm})$} \\
\hline Área & $0-5$ & $5-10$ & $10-20$ & $\begin{array}{c}0-20 \\
\text { (média) }\end{array}$ & $\mathrm{RE}^{*}$ \\
\hline \multicolumn{6}{|c|}{-----------------------\% \%----------------------- } \\
\hline $\begin{array}{l}\text { Café } \\
\text { orgânico }\end{array}$ & 3,30 a A & $\begin{array}{c}2,65 \mathrm{~b} B \\
(20)\end{array}$ & $\begin{array}{c}2,79 \mathrm{~b} \mathrm{~B} \\
(7)\end{array}$ & $\begin{array}{c}2,91 \mathrm{~b} \\
(10)\end{array}$ & $1,18 \mathrm{a}$ \\
\hline $\begin{array}{l}\text { Café con- } \\
\text { vencional }\end{array}$ & $\begin{array}{c}2,84 \mathrm{~b} \mathrm{~A} \\
\quad(18)\end{array}$ & $\begin{array}{c}2,45 \mathrm{~b} B \\
(26)\end{array}$ & $\begin{array}{c}2,55 \mathrm{c} B \\
(15)\end{array}$ & $\begin{array}{c}2,61 \mathrm{c} \\
(20)\end{array}$ & $1,11 \mathrm{a}$ \\
\hline Mata & 3,46 a A & 3,31 a A & 2,99 a A & $3,25 \mathrm{a}$ & $1,16 \mathrm{a}$ \\
\hline
\end{tabular}

À exceção da área de mata, que não apresentou diferenças nos teores de COT para as profundidades estudadas, os manejos do cafeeiro mostraram uma tendência de diminuição dos teores de COT nas camadas mais profundas. Resultados semelhantes foram encontrados por Rangel e colaboradores, ${ }^{32}$ ao se estudar a dinâmica da matéria orgânica do solo em diversos espaçamentos de plantio de lavouras cafeeiras. Na camada mais superficial $(0-5 \mathrm{~cm})$, os teores de COT das áreas de café orgânico e mata foram maiores que os observados na área com café convencional. Na lavoura orgânica, pelo uso mais intensivo de adubos verdes (p.e. Crotalaria juncea e Cajanus cajan), há uma maior quantidade de $\mathrm{C}$ adicionado pelas raízes destas plantas, pois, o desenvolvimento radicular de adubos verdes pode contribuir para aumentar os teores de COT até $10 \mathrm{~cm}$ de profundidade do solo. ${ }^{33}$

Em sistemas agrícolas tropicais pode haver uma diminuição de até $50 \%$ nos teores originais de matéria orgânica do solo, em menos de 10 anos de cultivo. ${ }^{5} \mathrm{Na}$ Tabela 2 verifica-se que, independente do manejo, a diminuição média nas profundidades de 0-5 e 5-10 cm não foi tão expressiva, ficando próxima da média de $22 \%$ observada para lavouras cafeeiras. ${ }^{34}$ Isso pode ser atribuído ao baixo revolvimento do solo nas lavouras cafeeiras, e conseqüente baixa exposição dos compostos orgânicos a condições de oxidação. Em geral, as maiores perdas acumuladas de COT foram observadas para o café convencional, em todas as profundidades avaliadas (Tabela 2). Considerando a profundidade total de $0-20 \mathrm{~cm}$, observa-se que o cultivo de café orgânico, com maior aporte de C, via adubos orgânicos/verdes, apresentou uma redução de 
somente $10 \%$, em relação ao teor original de C, ante a redução de $20 \%$ observada para o teor de COT no cultivo convencional.

O COT é um indicador da qualidade do solo capaz de evidenciar mudanças decorrentes do manejo no longo prazo ${ }^{6}$ refletindo, de certo modo, o histórico do manejo em relação às áreas nativas. Portanto, de maneira geral, a introdução de cultivos de café acarreta perdas nos teores de COT nas áreas estudadas da sub-bacia do Rio das Mortes. Contudo, a adoção do manejo orgânico propiciou uma recuperação e/ ou minimização das perdas de COT nas áreas estudadas (Tabela 2).

$\mathrm{O}$ valor de RE igual a 2,0 é tido como o limite entre os manejos convencional e conservacionista. ${ }^{9}$ Contudo, neste estudo, foram identificados valores de RE diferentes daqueles estabelecidos, ou seja, valores significativamente sem diferença para todas as situações, entre $1,1 \mathrm{e}$ 1,2 (Tabela 2). Logo, para áreas de cafeicultura da sub-bacia do Rio das Mortes, o indicador RE não se mostrou sensível para discriminar diferenças quanto à qualidade química da matéria orgânica do solo.

Dentre as frações de $\mathrm{C}$ associadas à matéria orgânica, a fração leve é o compartimento que se encontra em menor estágio de decomposição. A correlação positiva e altamente significativa (Tabela 3 ) evidencia a importância desse compartimento para o COT (C-FL/COT) (Tabela 4), sobretudo para o manejo orgânico, quando comparado ao convencional, e este em comparação com a mata. ${ }^{32} \mathrm{O}$ fato de o C-FL contribuir mais para o COT tem consequiências positivas para a qualidade química do solo, uma vez que se trata da presença de $\mathrm{C}$ de maior biodisponibilidade, capaz, portanto, de fornecer energia e nutrientes para microrganismos e plantas, garantindo a permanência de processos essenciais ao funcionamento do solo como componente do ecossistema.

Conforme foi verificado para o COT, o cultivo diminuiu os teores de C-FL entre 37 e $72 \%$, em relação ao solo sob vegetação nativa (Tabela 4). Este fato pode ser atribuído, em parte, à prática de arruação, comum na época da colheita (época da amostragem) e que consiste na retirada de todos os restos vegetais da área de projeção da copa do cafeeiro (local de amostragem neste estudo) e concentração desses restos na entrelinha. Valores de C-FL maiores na entrelinha que na área de projeção da copa foram observados em diversos espaçamentos de plantio de cafeeiro. ${ }^{32}$ As diferenças entre os manejos (Tabela 4) podem ser atribuídas ao maior uso de adubos orgânicos e verdes no manejo orgânico, ${ }^{18}$ além de maior presença de gramíneas (com predominância de Brachiaria spp.) na área sob esse manejo. As gramíneas, por apresentarem uma alta taxa de renovação do seu sistema radicular, podem contribuir para aumentar os teores de C-FL nas lavouras orgânicas, sobretudo quando for grande a quantidade de pêlos radiculares. ${ }^{35}$

De modo geral, houve maiores teores de C-AH na camada de $0-5 \mathrm{~cm}$ que nas demais profundidades (Tabela 5). Para os teores de C-AF ocorreu o contrário, ou seja, seus teores foram maiores nas duas camadas mais profundas. Assim, os valores das relações $\mathrm{C}-\mathrm{AH} / \mathrm{C}-\mathrm{AF}$
Tabela 3. Coeficientes de correlação linear entre os compartimentos da matéria orgânica para as áreas de cafeicultura ( $\mathrm{n}=15$; incluindo área-referência)

\begin{tabular}{lccc}
\hline Compartimentos & COT & C-FL & C-AH \\
\hline C-FL & $0,96^{* *}$ & & \\
C-AH & $-0,99^{* * *}$ & $-0,91^{* *}$ & \\
C-AF & $0,89^{*}$ & $0,73^{\text {ns }}$ & $-0,95^{* *}$ \\
\hline$* * *$ significativo a $1 \% ; * *$ significativo a $5 \% ; *$ significativo a $10 \% ;$ \\
ns não significativo (t-Student). COT = C orgânico total; C-FL = C na \\
fração leve; C-AH = C ácido húmico; C-AF = C ácido fúlvico.
\end{tabular}

Tabela 4. Teores de carbono na fração leve (C-FL) e C-FL como função do carbono orgânico total (C-FL/COT), presentes na camada mais superficial $(0-5 \mathrm{~cm})$ de solo sob cafeicultura

\begin{tabular}{llc}
\hline Área & C-FL $\left(\mathrm{mg} \mathrm{g}^{-1}\right)$ & C-FL/COT (\%) \\
\hline Café orgânico & $2,88 \mathrm{~b}(37)$ & $8,50 \mathrm{~b}(35)$ \\
Café convencional & $1,26 \mathrm{c}(72)$ & $4,40 \mathrm{c}(66)$ \\
Mata & $4,54 \mathrm{a}$ & $12,99 \mathrm{a}$ \\
\hline
\end{tabular}

Valores seguidos de letras iguais não diferem entre si pelo teste de Scott-Knott $(\mathrm{p} \leq 0,05)$. Valores entre parênteses referem-se à diminuição percentual do C-FL em relação à mata.

acompanharam as tendências acima, sendo maiores na profundidade de $0-5 \mathrm{~cm}$. Isso pode ser fruto de uma maior mobilidade do $\mathrm{C}-\mathrm{AF}$ da camada superficial $(0-5 \mathrm{~cm})$ em direção às duas camadas mais profundas $(5-10$ e $10-20 \mathrm{~cm})$ do perfil do solo, favorecendo aumento da relação C-AH/C-AF nestas camadas ${ }^{33}$ (Tabela 5).

Os AF, por englobarem moléculas de menor massa molar ${ }^{22} \mathrm{e}$ apresentarem mais grupos carboxílicos, ${ }^{20}$ são mais reativos e, conseqüentemente, mais propensos a perdas por lixiviação que os $\mathrm{AH}{ }^{22} \mathrm{O}$ manejo convencional propiciou os maiores teores de C-AH em solo, independente da profundidade avaliada. Nesse sistema de cultivo, nas profundidades de 0-5 e 10-20 cm, foram verificados os menores teores de C-AF. Na Tabela 2 pode-se observar que as profundidades de $0-5 \mathrm{e}$ $10-20 \mathrm{~cm}$ do solo sob manejo convencional apresentaram os menores teores de COT, sugerindo, portanto, uma perda de $\mathrm{C}$ na forma de $\mathrm{AF}$. Isto pode ser corroborado pela correlação negativa e significativa entre C-AF e C-AH (Tabela 3), ou seja, pode estar havendo uma transformação da forma $\mathrm{AH}$ para $\mathrm{AF}$, levando à perda desta última.

Valores de C-AH/C-AF iguais a 1,70 e 1,15 foram observados para cultivos de cafeeiro e mata nativa, respectivamente, para a profundidade de $0-10 \mathrm{~cm}$, enquanto que para a profundidade de $10-20 \mathrm{~cm}$ esses valores foram 1,94 e 1,23, respectivamente. ${ }^{34}$ A manutenção de uma relação $\mathrm{C}-\mathrm{AH} / \mathrm{C}-\mathrm{AF}$ mais alta é importante na conservação do

Tabela 5. Teores de carbono $\left(\mathrm{mg} \mathrm{g}^{-1}\right)$ nas de frações ácidos húmico $(\mathrm{C}-\mathrm{AH})$ e fúlvico $(\mathrm{C}-\mathrm{AF})$ e relação entre estas frações $(\mathrm{C}-\mathrm{AH} / \mathrm{C}-\mathrm{AF})$ em três profundidades de solo sob cafeicultura

\begin{tabular}{|c|c|c|c|c|}
\hline Profundidade & Manejo & $\mathrm{C}-\mathrm{AH}$ & C-AF & C-AH/C-AF \\
\hline \multirow{3}{*}{$0-5 \mathrm{~cm}$} & Orgânico & $2,40 \mathrm{~b} \mathrm{~A}$ & 0,98 a B & $2,45 \mathrm{~b} \mathrm{~A}$ \\
\hline & Convencional & 3,35 a A & $0,34 \mathrm{~b}$ B & 9,85 a A \\
\hline & Mata & $2,29 \mathrm{~b} \mathrm{~A}$ & 0,83 a B & $2,75 \mathrm{~b} \mathrm{~A}$ \\
\hline \multirow{3}{*}{$5-10 \mathrm{~cm}$} & Orgânico & 0,49 b B & 2,50 a A & $0,20 \mathrm{~b} \mathrm{~B}$ \\
\hline & Convencional & 2,03 a A & 2,02 a A & 1,00 a B \\
\hline & Mata & $0,83 \mathrm{~b} \mathrm{~B}$ & 2,75 a A & $0,30 \mathrm{~b} \mathrm{~B}$ \\
\hline \multirow{3}{*}{$10-20 \mathrm{~cm}$} & Orgânico & $1,06 \mathrm{~b} \mathrm{~B}$ & 2,27 a A & $0,47 \mathrm{~b} B$ \\
\hline & Convencional & 2,60 a A & $1,82 \mathrm{~b} \mathrm{~A}$ & 1,43 a B \\
\hline & Mata & 1,39 b B & 2,48 a A & 0,56 b B \\
\hline
\end{tabular}

Valores seguidos de letras iguais não diferem entre si (Scott-Knott, $\mathrm{p} \leq 0,05$ ); letras minúsculas comparam tipos de manejo, dentro de cada profundidade (colunas); letras maiúsculas comparam profundidades dentro de cada manejo (colunas). 
$\mathrm{C}$ do solo em forma mais condensada e menos propensa a perdas. ${ }^{18}$ Pela análise da Tabela 5 poder-se-ia inferir algo similar, mas há que se ter cuidado ao se interpretar os valores para os manejos e mata nativa. Os altos valores de C-AH/C-AF para o manejo convencional, neste caso, não são um indicativo da superioridade deste e sim um reflexo dos baixos teores de $\mathrm{C}-\mathrm{AF}$, provavelmente devido a uma maior mineralização dos compostos orgânicos de massa molar mais baixa ${ }^{23}$ e, ou, sua lixiviação. ${ }^{18}$ Tudo indica que o manejo orgânico se destaca pela manutenção de todos os atributos das substâncias húmicas significativamente sem diferença em relação à mata (Tabela 5).

\section{CONCLUSÕES}

Em relação à área de mata nativa, o cultivo do cafeeiro causou uma diminuição nos teores de carbono orgânico total e C-fração leve. Independente do manejo, os maiores teores de carbono orgânico total foram observados na profundidade de $0-5 \mathrm{~cm}$ do solo. A razão de estratificação não se mostrou sensível para distinguir os sistemas de manejo do solo quanto às prováveis perdas de matéria orgânica nas áreas cultivadas. Dentre os indicadores químicos avaliados, o carbono orgânico total e o C-fração leve apresentaram as melhores capacidades de diferenciação da qualidade química da matéria orgânica do solo em função do manejo. O manejo orgânico propiciou relação C-AH/C$\mathrm{AF}$ igual à referência e os teores de $\mathrm{C}$-fração leve e $\mathrm{C}$ orgânico total nesse sistema de cultivo superaram em 128 e $12 \%$, respectivamente, os observados na área de cafeeiro sob manejo convencional. O manejo orgânico do cafeeiro se destacou pela manutenção de todos os atributos químicos da matéria orgânica em condições similares à mata nativa, contribuindo para uma maior sustentabilidade das áreas de produção de café da sub-bacia do Rio das Mortes.

\section{AGRADECIMENTOS}

À Fapemig pelo custeio do projeto de pesquisa (processo CAG 1128/03), à CAPES pela cessão de bolsa de Doutorado ao primeiro autor, aos proprietários das fazendas Cachoeira (Sra. M. M. de Aguiar) e Taquaril (Sr. D. Paiva) por, gentilmente, cederem suas áreas de cultivo para a coleta de amostras de solo e realização deste estudo.

\section{REFERÊNCIAS}

1. http://www.ibge.gov.br/cidadesat/default.php, acessada em Abril 2007.

2. Altieri, M.; Agroecologia: bases científicas para a agricultura sustentável, Agropecuária: Guaíba, 2002.

3. Bayer, C.; Dick, D. P.; Ribeiro, M.; Scheuermann, K. K.; Ci. Rural 2002, $32,401$.

4. Doran, J. W.; Parkin, T. B. Em Methods for assessing soil quality; Doran, J. W.; Jones, A. J., eds.; SSSA: Madison, 1996.

5. Mielniczuk, J.; Bayer, C.; Vezzani, F. M.; Lovato, T.; Fernandes, F. F.; Debarba, L. Em Tópicos em ciência do solo; Curi, N.; Marques, J. J.; Guilherme, L. R. G.; Lima, J. M.; Lopes, A. S.; Alvarez V., V. H., eds.; SBCS: Viçosa, 2003, cap. 5.

6. Conceição, P. C.; Amado, T. J. C.; Mielniczuk, J.; Spangnollo, E.; $R$. Bras. Ci. Solo 2005, 29, 777.

7. Canellas, L. P.; Velloso, A. C. X.; Marciano, C. R.; Ramalho, J. F. G. P.; Rumjanek, V. M.; Rezende, C. E.; Santos, G. A.; R. Bras. Ci. Solo 2003 27, 935. (CA 141:53650)

8. Baldock, J. A.; Nelson, P. N. Em Handbook of soil Science; Sumner, M.
E., ed.; CRC Press: Boca Raton, 2000.

9. Franzluebbers, A. J.; Soil Tillage Res. 2002, 66, 95.

10. Mielniczuck, J. Em Fundamentos da matéria orgânica: ecossistemas tropicais e subtropicais; Santos, G. A.; Camargo, F. A. O., eds.; Gênesis: Porto Alegre, 1999.

11. Stevenson, F. J.; Humus chemistry: genesis, composition, reactions, $2^{\text {nd }}$ ed., Wiley: New York, 1994.

12. Freixo, A. A.; Machado, P. L. O. A.; Santos, H. P.; Silva, C. A.; Fadigas, F. S.; Soil Tillage Res. 2002, 64, 221.

13. Silva, J. E.; Resck, D. V. S. Em Biologia dos solos dos cerrados; Vargas, M. T.; Hungria, M., eds.; Embrapa-CPAC: Planaltina, 1997.

14. Janzen, H. H.; Campbell, C. A.; Bradt, S. A.; Lafond, G. P.; TownleySmith, L.; Soil Sci. Soc. Am. J. 1992, 56, 1799.

15. Silva, I. R.; Mendonça, E. S. Em Fertilidade do solo; Novais, R. F.; Alvarez V., V. H.; Barros, N. F.; Fontes, R. L. F.; Canarutti, R. B.; Neves, J. C. L., eds.; SBCS: Viçosa, 2007.

16. Canellas, L. P.; Berner, P. G.; Silva, S. G.; Silva, M. B.; Santos, G. A.; Pesq. Agrop. Bras. 2000, 35, 133.

17. Anderson, J. M.; Ingram, J. S. I.; Tropical soil biology and fertility: a handbook of methods, $2^{\text {nd }}$ ed., CAB International: Wallingford, 1993.

18. Leite, L. F. C.; Mendonça, E. S.; Neves, J. C. L.; Machado, P. L. O. A.; Galvão, J. C. C.; R. Bras. Ci. Solo 2003, 27, 821.

19. Camargo, F. A. O.; Santos, G. A.; Guerra, J. G. M. Em ref. 10

20. Colombo, S. M.; Santos, L. B. O.; Masini, J. C.; Abate, G.; Quim. Nova 2007, 30, 1261

21. Canellas, L. P.; Espindola, J. A. A.; Rezende, C. E.; Camargo, P. B.; Zandonadi, D. B.; Rumjanek, V. M.; Guerra, J. G. M.; Teixeira, M. G.; Braz-Filho, R.; Scientia Agricola 2004, 61, 53. (CA 141:313552)

22. Marschner, B.; Wilczynski, W.; Plant Soil 1991, 137, 229. (CA 116:20239)

23. Machado, P. L. O. A.; Gerzabeck, M. H.; Soil Tillage Res. 1993, 26, 227.

24. Slepetiene, A.; Slepetys, J.; Geoderma 2005, 127, 207. (CA 144:273559)

25. Watanabe, A.; Sarno, J.; Rumbanraja, K.; Tsutsuki, K.; Kimura, M.; Eur. J. Soil Sci. 2001, 52, 599. (CA 137:62714)

26. Theodoro, V. C. A.; Alvarenga, M. I. N.; Guimarães R. J.; Souza, C. A. S.; R. Bras. Ci. Solo 2003, 27, 1039.

27. Empresa Brasileira de Pesquisa Agropecuária; Manual de métodos de análises de solo, 2a ed.; CNPS: Rio de Janeiro, 1997.

28. Yeomans, J. C.; Bremner, J. M.; Commun. Soil Sci. Plant Anal. 1988, 19, 1467. (CA 109:127892)

29. Machado, P. L. O.; Fracionamento físico do solo por densidade e granulometria para a quantificação de compartimentos da matéria orgânica do solo - um procedimento para estimativa pormenorizada do seqüestro de carbono pelo solo, Embrapa Solos: Rio de Janeiro, 2002.

30. Benites, V. M.; Madari, B.; Machado, P. L. O. A.; Extração e fracionamento quantitativo de substâncias húmicas do solo: um procedimento simplificado de baixo custo, Embrapa Solos: Rio de Janeiro, 2003.

31. Melero, S.; Porras, J. C. R.; Herencia, E. M.; Soil Tillage Res. 2006, 90 , 162.

32. Rangel, O. J. P.; Silva, C. A.; Guimarães, P. T. G.; R. Bras. Ci. Solo 2007, 31, 1341

33. Souza, W. J. O.; Melo, W. J.; R. Bras. Ci. Solo 2003, 27, 1113

34. Marchiori Junior, M.; Melo, W. J.; Pesq. Agrop. Bras. 2000, 35, 1177.

35. Puget, P.; Drinkwater, L. E.; Soil Sci. Soc. Am. J. 2001, 65, 771. (CA 2001:711768) 